\title{
Effect of proximity to specialty care on outcomes for biliary cancers: a population-based retrospective cohort study
}

\author{
Yuan Xu MD PhD, Sue Steckle MSc MBA, Arthur Lui MD, Elijah Dixon MD MPH, \\ Chad G. Ball MD MSc, Francis R. Sutherland MD, Jennifer Spratlin MD, Oliver F. Bathe MD MSc
}

\section{Abstract}

Background: The management of biliary cancers is complex and requires a multidisciplinary approach. Because it is unknown how access to specialty care affects resource use and survival in patients with biliary cancer, we conducted a population-based study to understand the needs of these patients and the relation of geography to care delivery and clinical outcomes for biliary cancer in Alberta.

\begin{abstract}
Methods: All patients with biliary cancer diagnosed in Alberta from Sept. 1, 2001, to Dec. 31, 2015 were included in this populationbased retrospective cohort study. Data were extracted from administrative databases and the 2011 Canadian census. Driving time and types of medical services were tracked throughout the patients' clinical course. We categorized proximity to specialty care according to driving time to the nearest specialist. The primary outcome was overall survival. We conducted Cox proportional hazard regression to evaluate the effects of driving time on overall survival and multivariate logistic regression to evaluate the effect of driving time on treatment types and stage at diagnosis.
\end{abstract}

Results: We identified 1610 patients with biliary cancer; they accounted for 117381 medical encounters. Patients living 120 minutes or more from the nearest hepatobiliary surgeon and from the nearest cancer centre had significantly decreased survival (hazard ratio [and 95\% confidence interval $(\mathrm{Cl})$ ] 1.27 [1.17-1.37]) and 1.27 [1.14-1.41], respectively). Location of residence was not associated with advanced stage or probability of undergoing surgery or a biliary drainage procedure. Patients who lived 120 minutes or more from a cancer centre were less likely than those who lived less than 120 minutes away to receive chemotherapy (odds ratio 0.51 , $95 \% \mathrm{Cl}$ 0.29-0.88). Subgroup analysis showed that the effect of travel time was especially pronounced among those who received only best supportive care and those who had biliary drains.

Interpretation: Geography and accessibility to specialty care affected survival in patients with biliary cancer. Further study is required to understand how patients with biliary drains and those receiving best supportive care are affected by proximity to specialty care. This will aid in the identification of strategies to provide improved care for this subgroup who are particularly affected by geography.

$\mathrm{B}$ iliary cancers are rare tumours that are generally associated with a poor prognosis. Surgery is the only potential cure, although only a minority of tumours are candidates for resection. ${ }^{1}$ Moreover, surgery is technically difficult and is associated with very high morbidity and mortality rates. ${ }^{2,3}$ In patients with advanced disease and adequate performance status, palliative chemotherapy is advantageous. ${ }^{4}$ However, the disease is often complicated by jaundice and sometimes sepsis, precluding chemotherapy. The mainstay of palliation consists of achieving stable biliary drainage, which generally necessitates repeated instrumentation of the biliary tract over the disease course. ${ }^{5-7}$ In all, the management of biliary cancers is complex and requires the coordination of multiple specialties.

For the optimal management of biliary cancers, it is important that a patient have sufficient planned and emergent access to appropriate facilities and specialists including hepatobiliary surgeons, oncologists and interventional radiologists. Continuity of care is important to ensure management plans are followed. For patients living far from major population centres, these features of care are difficult to deliver. Our objective was to understand what disparities of care exist as a function of driving time to tertiary and quaternary care facilities in Alberta and how these disparities affect survival. Few data are available that provide a comprehensive picture of the needs of patients with biliary cancer, from diagnosis to death.

\section{Competing interests: None declared.}

This article has been peer reviewed.

Correspondence to: Oliver Bathe, bathe@ ucalgary.ca

CMAJ Open 2019. DOI:10.9778/cmajo.20180082 
Given the need for highly expert care, we postulated that patients who lived more remotely would have worse survival.

\section{Methods}

\section{Study population and data sources}

The province of Alberta consists of an area of $660000 \mathrm{~km}^{2}$ with a population of 4 million. About $20 \%$ of the population lives in rural areas. In this population-based retrospective cohort study, we included all cases of biliary cancer diagnosed in Alberta from Sept. 1, 2001, to Dec. 31, 2015. This included intrahepatic cholangiocarcinoma, extrahepatic cholangiocarcinoma, gallbladder cancer and ampullary cancer, all of adenocarcinoma histologic type.

Data were extracted from the Alberta Cancer Registry, physician billing claims, hospital discharge abstracts, ambulatory care records, the provincial population registry and the 2011 Canadian census. The Alberta Cancer Registry records patient demographic characteristics, treatments, diagnosis date, last date of follow-up, vital statistics and tumour characteristics including tumour type and American Joint Committee on Cancer stage. It has received gold-level certification status from the North American Association of Central Cancer Registries, which has standardized cancer registry data since 2014 (https://www.naaccr.org/certified -registries/). We used physician claims data to track medical encounters. Hospital discharge abstracts describe up to 25 diagnoses coded with the International Statistical Classification of Diseases and Related Health Problems, 10th revision (ICD-10) and up to 20 procedures described by Canadian Classification of Health Interventions codes. Data were linked by provincial health number. We calculated the Charlson Comorbidity Index score for each patient within a year of diagnosis using validated algorithms. ${ }^{8}$ We derived neighbourhood socioeconomic status including average income and proportion with a postsecondary education from census data. The administrative data sets and ICD codes were previously validated..$^{8-10}$

We used patient postal code to calculate driving time to the nearest facility with a hepatopancreatobiliary surgeon and to the nearest cancer centre (Table 1). We calculated travel times for each medical visit based on patient and medical facility postal codes. All driving times were calculated with the use of Google Maps application programming interfaces, ${ }^{11}$ based on driving times at noon on a weekday. Previous publications did not provide a standard on how to categorize driving time. Our driving time categories $(\leq 30 \mathrm{~min}$, 31-60 $\mathrm{min}, 61-120 \mathrm{~min}, 121-180 \mathrm{~min}$ and > $180 \mathrm{~min}$ ) were based on our own estimates of meaningful proximity intervals.

\section{Outcomes}

The primary outcome was overall survival, beginning from the date of tissue diagnosis or the first biliary intervention, whichever was first. Secondary outcomes included the proportion of patients with delayed diagnosis and treatments delivered.

\section{Statistical analysis}

We performed statistical analysis using SAS version 9.4 (SAS Institute) and data visualization using Tableau version 10.3 (Tableau Software). We used descriptive statistics to characterize the study cohort. We compared continuous data using the $t$ test and used the $\chi^{2}$ test for comparison of categorical variables. We conducted Cox proportional hazard regression to evaluate the effects of driving time on overall survival. Based on previously published studies, ${ }^{12-14}$ we included key risk factors in the models, including age, sex, neighbourhood socioeconomic status, resection, chemotherapy, tumour type (intrahepatic cholangiocarcinoma, extrahepatic cholangiocarcinoma, gallbladder cancer or ampullary cancer), presence of stage IV disease, year of diagnosis (from 2001 to 2015) and Charlson Comorbidity Index for the entire cohort and subgroups. We conducted multivariate logistic regression to evaluate the effect of driving time on treatment types (adjusted for age, sex, Charlson Comorbidity Index score, stage, tumour type, year of diagnosis and socioeconomic status) and on stage at diagnosis (adjusted for age, sex, Charlson Comorbidity Index score, tumour type, year and socioeconomic status). A 2 -sided $p$ value $\leq 0.05$ was considered statistically significant.

In tracking medical visits, we considered 3 intervals during each patient's disease trajectory. The prediagnosis interval included the 3 months before the date of diagnosis, the postdiagnosis interval was 24 months from the date of diagnosis, and the end-of-life interval included the final 8 weeks of life. For patients whose lifespan (after diagnosis) was 8 weeks or less, only activity in the final interval could be described.

\section{Ethics approval}

This study was approved by the Health Research Ethics Board of Alberta Cancer Committee.

\section{Results}

\section{Incidence and geographic distribution of biliary cancers}

During the study period, 1717 cases of biliary cancer were diagnosed. Among these, 107 patients (6.2\%) had invalid provincial health numbers (nonresidents of Alberta) or no followup after diagnosis or primary treatment and were excluded, leaving 1610 patients for analysis (396 with extrahepatic cholangiocarcinoma, 386 with intrahepatic cholangiocarcinoma, 531 with gallbladder cancer and 243 with ampullary cancer; the remaining 54 patients had tumours that could not be classified because they were "not otherwise specified" or were at overlapping sites). The geographic case distribution throughout the province is depicted in Figure 1. Patient characteristics are summarized in Table 2 and Supplementary Table S1, Appendix 1 (available at www.cmajopen.ca/content/7/1/ E131/suppl/DC1). Of the 1610 patients, 114 (7.1\%) lived at least 120 minutes' driving time from the nearest cancer centre, and 245 (15.2\%) had to drive 120 minutes or more to the nearest hepatopancreatobiliary surgeon. In all, 975 patients $(60.6 \%)$ received best supportive care, 262 (16.3\%) received 


\begin{tabular}{|c|c|c|}
\hline Institution type & Institution & City/town \\
\hline \multirow[t]{6}{*}{ Cancer centre } & Cross Cancer Institute & Edmonton \\
\hline & Tom Baker Cancer Centre & Calgary \\
\hline & Central Alberta Cancer Centre & Red Deer \\
\hline & Jack Ady Cancer Centre & Lethbridge \\
\hline & Grande Prairie Cancer Centre & Grande Prairie \\
\hline & Margery E. Yuill Cancer Centre & Medicine Hat \\
\hline \multirow{3}{*}{$\begin{array}{l}\text { Centre with } \\
\text { hepatopancreatobiliary } \\
\text { surgeons }\end{array}$} & University of Alberta Hospital & Edmonton \\
\hline & Foothills Medical Centre & Calgary \\
\hline & Red Deer Regional Hospital & Red Deer \\
\hline \multirow{26}{*}{$\begin{array}{l}\text { Centre with general } \\
\text { surgeons }\end{array}$} & Foothills Medical Centre & Calgary \\
\hline & University of Alberta Hospital & Edmonton \\
\hline & Peter Lougheed Centre & Calgary \\
\hline & Red Deer Regional Hospital & Red Deer \\
\hline & Royal Alexandra Hospital & Edmonton \\
\hline & Sturgeon Community Hospital & St. Albert \\
\hline & Chinook Regional Hospital & Lethbridge \\
\hline & Rockyview General Hospital & Calgary \\
\hline & Queen Elizabeth II Hospital & Grand Prairie \\
\hline & Misericordia Community Hospital & Edmonton \\
\hline & Grey Nuns Community Hospital & Edmonton \\
\hline & Medicine Hat Regional Hospital & Medicine Hat \\
\hline & Stollery Children's Hospital & Edmonton \\
\hline & Fort Saskatchewan Community Hospital & Fort Saskatchewan \\
\hline & St. Mary's Hospital & Camrose \\
\hline & South Health Campus & Calgary \\
\hline & Northern Lights Regional Health Centre & Fort McMurray \\
\hline & Hinton General Hospital & Hinton \\
\hline & Cold Lake Hospital & Cold Lake \\
\hline & Drumheller Health Centre & Drumheller \\
\hline & Canmore General Hospital & Canmore \\
\hline & Crowsnest Pass Health Centre & Crowsnest Pass \\
\hline & Strathcona Community Hospital & Sherwood Park \\
\hline & Wetaskiwin Hospital and Care Centre & Wetaskiwin \\
\hline & Alberta Children's Hospital & Calgary \\
\hline & St. Therese - St. Paul Healthcare Centre & St. Paul \\
\hline
\end{tabular}

chemotherapy alone, $262(16.3 \%)$ received surgery alone, and $103(6.4 \%)$ received surgery and chemotherapy.

\section{Survival as a function of residence}

The median length of follow-up among the 1299 patients $(80.7 \%)$ followed until death was 6.8 months (interquartile range [IQR] 2.5-16.8 mo). The median length of follow-up for the remaining 311 patients was 49.9 months (IQR 23.1$92.9 \mathrm{mo}$ ). As expected, median survival was best among patients who underwent resection $(35.6 \mathrm{mo}, 95 \%$ confidence interval [CI 26.2-49.6 mo), followed by patients who had palliative chemotherapy (12.0 mo, 95\% CI 10.6-13.4 mo); it was worst among patients who received best supportive care $(4.6 \mathrm{mo}$, $95 \%$ CI 4.1-5.1 mo). Survival for ampullary cancer (24.5 mo, 95\% CI 18.9-27.2 mo) was considerably better than that for intrahepatic cholangiocarcinoma (5.7 mo, 95\% CI 4.7-7.0 mo), extrahepatic cholangiocarcinoma $(10.2 \mathrm{mo}, 95 \%$ CI $9.1-$ $12.5 \mathrm{mo})$ and gallbladder cancer $(8.0 \mathrm{mo}, 95 \% \mathrm{CI} 6.7-9.6 \mathrm{mo})$. 


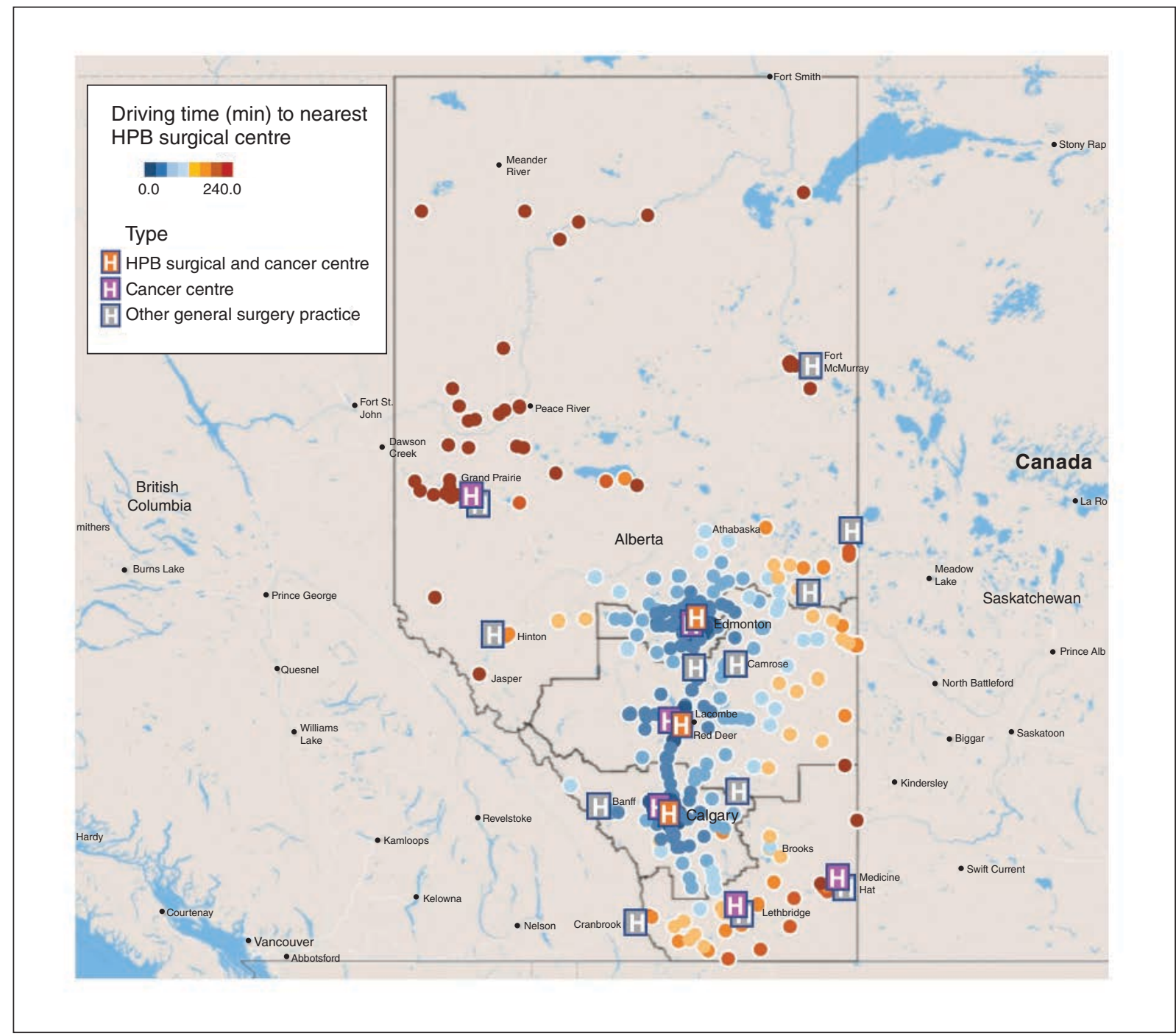

Figure 1: Geographic distribution of cases of biliary cancers in the province of Alberta between 2001 and 2015. Main population centres, cancer centres and sites where hepatopancreatobiliary (HPB) surgeons exist are marked.

Without adjustment for other factors, overall survival was not significantly different according to driving time to the nearest hepatopancreatobiliary surgeon, cancer centre or interventional radiologist (Table 2 and Supplementary Table S1, Appendix 1). However, longer driving time to the nearest hepatopancreatobiliary surgeon and to the nearest cancer centre were significantly associated with decreased survival $(p<0.001$ and $p=0.001$, respectively), after adjustment for age, sex, comorbidities, income and education levels, treatment (surgery or chemotherapy), stage and tumour type. Although driving time was significant as a continuous variable, the association was particularly pronounced for driving time of 120 minutes or more: living at least 120 minutes from the nearest hepatopancreatobiliary surgeon was associated with decreased survival (hazard ratio [HR] 1.27, 95\% CI 1.17-1.37) (Table 3), as was living 120 minutes or more from the nearest cancer centre (HR 1.27, 95\% CI 1.14-1.41) (Supplementary Table S1, Appendix 1). In the multivariate model, survival outcomes were better in cancers diagnosed from 2010 onward (HR 0.84, 95\% CI 0.79-0.89) (Table 3), and the number of biliary drains was also a significant factor associated with survival (HR 0.97, 95\% CI 0.95-0.98) (Table 3).

Further analyses focused on outcomes as a function of driving time to the nearest hepatopancreatobiliary surgeon $(\geq 120 \mathrm{~min} v .<120 \mathrm{~min}$ ), since that had the greatest impact on survival. Subgroup analysis showed that the effect on survival of driving time to the nearest hepatopancreatobiliary surgeon was pronounced for older patients, those with a lower Charlson Comorbidity Index score, those who received best supportive care and those who had biliary drainage (Figure 2). In the tumour type subgroups, the effect of driving time was greatest for ampullary cancer, followed by intrahepatic cholangiocarcinoma.

\section{Disease stage and treatment as a function of residence}

Treatment strategies changed during the study period. The proportion of patients with extrahepatic cholangiocarcinoma, 


\begin{tabular}{|c|c|c|c|c|c|c|c|}
\hline \multirow[b]{2}{*}{ Variable } & \multicolumn{6}{|c|}{ Driving time, min; no. (\%) of patients* } & \multirow[b]{2}{*}{$p$ value } \\
\hline & $\begin{aligned} & \leq 30 \\
n & =974\end{aligned}$ & $\begin{array}{r}31-60 \\
n=237\end{array}$ & $\begin{array}{l}61-120 \\
n=154\end{array}$ & $\begin{array}{l}121-180 \\
n=128\end{array}$ & $\begin{array}{r}>180 \\
n=117\end{array}$ & $\begin{array}{c}\text { Total } \\
n=1610\end{array}$ & \\
\hline \multicolumn{8}{|l|}{ Sex } \\
\hline Female & $524(53.8)$ & $115(48.5)$ & $73(47.4)$ & $67(52.3)$ & $61(52.1)$ & $840(52.2)$ & 0.4 \\
\hline Male & $450(46.2)$ & $122(51.5)$ & $81(52.6)$ & $61(47.7)$ & $56(47.9)$ & $770(47.8)$ & \\
\hline Age, yr, mean \pm SD & $67.6 \pm 13.0$ & $65.4 \pm 12.8$ & $67.5 \pm 11.5$ & $67.7 \pm 12.7$ & $64.8 \pm 13.5$ & $67.1 \pm 12.9$ & 0.05 \\
\hline \multicolumn{8}{|l|}{$\begin{array}{l}\text { Charlson Comorbidity Index } \\
\text { score }\end{array}$} \\
\hline$\leq 2$ & $391(40.1)$ & $95(40.1)$ & $64(41.6)$ & $46(35.9)$ & $52(44.4)$ & $648(40.2)$ & 0.9 \\
\hline $3-4$ & $251(25.8)$ & $59(24.9)$ & $37(24.0)$ & $36(28.1)$ & $24(20.5)$ & $407(25.3)$ & \\
\hline$\geq 5$ & $332(34.1)$ & $83(35.0)$ & $53(34.4)$ & $46(35.9)$ & $41(35.0)$ & $555(34.5)$ & \\
\hline \multicolumn{8}{|l|}{ Tumour type } \\
\hline $\begin{array}{l}\text { Intrahepatic } \\
\text { cholangiocarcinoma }\end{array}$ & $241(24.7)$ & $57(24.0)$ & $35(22.7)$ & $22(17.2)$ & $31(26.5)$ & $386(24.0)$ & 0.3 \\
\hline $\begin{array}{l}\text { Extrahepatic } \\
\text { cholangiocarcinoma }\end{array}$ & $332(34.1)$ & $76(32.1)$ & $53(34.4)$ & $43(33.6)$ & $27(23.1)$ & $396(24.6)$ & \\
\hline Gallbladder cancer & $232(23.8)$ & $56(23.6)$ & $42(27.3)$ & $36(28.1)$ & $30(25.6)$ & $531(33.0)$ & \\
\hline Ampullary cancer & $132(13.6)$ & $40(16.9)$ & $22(14.3)$ & $24(18.8)$ & $25(21.4)$ & $243(15.1)$ & \\
\hline Other/overlapping & $37(3.8)$ & $8(3.4)$ & $2(1.3)$ & $3(2.3)$ & $4(3.4)$ & $54(3.4)$ & \\
\hline \multicolumn{8}{|l|}{ Stage } \\
\hline I-III & $590(60.6)$ & $137(57.8)$ & $93(60.4)$ & $86(67.2)$ & $72(61.5)$ & $978(60.7)$ & 0.5 \\
\hline IV & $384(39.4)$ & $100(42.2)$ & $61(39.6)$ & $42(32.8)$ & $45(38.5)$ & $632(39.2)$ & \\
\hline \multicolumn{8}{|l|}{ Treatment } \\
\hline Surgery & $156(16.0)$ & $37(15.6)$ & $29(18.8)$ & $22(17.2)$ & $26(22.2)$ & $270(16.8)$ & 0.08 \\
\hline Chemotherapy & $169(17.4)$ & $48(20.2)$ & $14(9.1)$ & $13(10.2)$ & $18(15.4)$ & $262(16.3)$ & \\
\hline Chemotherapy + surgery & $56(5.7)$ & $20(8.4)$ & $9(5.8)$ & $9(7.0)$ & $9(7.7)$ & $103(6.4)$ & \\
\hline Best supportive care & $593(60.9)$ & $132(55.7)$ & $102(66.2)$ & $84(65.6)$ & $64(54.7)$ & $975(60.6)$ & \\
\hline \multicolumn{8}{|l|}{ No. of biliary drains } \\
\hline 0 & $450(46.2)$ & 105 (44.3) & $75(48.7)$ & $48(37.5)$ & $49(41.9)$ & $727(45.2)$ & 0.3 \\
\hline 1 & $230(23.6)$ & $56(23.6)$ & $36(23.4)$ & $31(24.2)$ & $34(29.1)$ & $387(24.0)$ & \\
\hline$\geq 2$ & $294(30.2)$ & $76(32.1)$ & $43(27.9)$ & 49 (38.3) & $34(29.1)$ & $496(30.8)$ & \\
\hline \multicolumn{8}{|l|}{ Year of diagnosis } \\
\hline Before 2010 & $493(50.6)$ & $99(41.8)$ & $92(59.7)$ & $62(48.4)$ & $63(53.8)$ & $809(50.2)$ & 0.01 \\
\hline 2010 onward & $481(49.4)$ & $138(58.2)$ & $62(40.3)$ & $66(51.6)$ & $54(46.2)$ & $801(49.8)$ & \\
\hline \multicolumn{8}{|c|}{ Overall survival length, mo, mean \pm SD } \\
\hline $\begin{array}{l}\text { Intrahepatic } \\
\text { cholangiocarcinoma }\end{array}$ & $12.7 \pm 19.4$ & $10.7 \pm 18.9$ & $11.1 \pm 12.2$ & $11.6 \pm 17.4$ & $10.3 \pm 13.4$ & $12.0 \pm 18.2$ & 0.7 \\
\hline $\begin{array}{l}\text { Extrahepatic } \\
\text { cholangiocarcinoma }\end{array}$ & $23.0 \pm 33.3$ & $20.4 \pm 29.8$ & $22.7 \pm 38.6$ & $21.0 \pm 30.2$ & $20.6 \pm 31.8$ & $22.2 \pm 32.9$ & \\
\hline Gallbladder cancer & $25.6 \pm 41.6$ & $18.6 \pm 33.3$ & $22.2 \pm 31.6$ & $14.0 \pm 22.8$ & $26.5 \pm 45.4$ & $23.3 \pm 38.6$ & \\
\hline Ampullary cancer & $35.5 \pm 36.3$ & $33.5 \pm 39.3$ & $40.0 \pm 47.4$ & $44.9 \pm 53.3$ & $22.2 \pm 22.5$ & $35.1 \pm 38.8$ & \\
\hline \multicolumn{8}{|c|}{ Neighbourhood education level (no. [\%] with high school or above) } \\
\hline$<75$ & $386(39.6)$ & $82(34.6)$ & $53(34.4)$ & $52(40.6)$ & $51(43.6)$ & $624(38.8)$ & 0.2 \\
\hline $75-85$ & $261(26.8)$ & $78(32.9)$ & 49 (31.8) & $40(31.2)$ & $40(34.2)$ & $468(29.1)$ & \\
\hline$>85$ & $327(33.6)$ & $77(32.5)$ & $52(33.8)$ & $36(28.1)$ & $26(22.2)$ & $518(32.2)$ & \\
\hline \multicolumn{8}{|c|}{ Neighbourhood income level (average annual income, \$) } \\
\hline$<35000$ & $341(35.0)$ & $69(29.1)$ & $49(31.8)$ & $51(39.8)$ & $48(41.0)$ & $558(34.7)$ & 0.2 \\
\hline $35000-50000$ & $360(37.0)$ & $98(41.4)$ & $57(37.0)$ & 49 (38.3) & $46(39.3)$ & $610(37.9)$ & \\
\hline$>50000$ & $273(28.0)$ & $70(29.5)$ & $48(31.2)$ & $28(21.9)$ & $23(19.7)$ & $442(27.4)$ & \\
\hline \multicolumn{8}{|c|}{ Average annual incidence per $100000(95 \% \mathrm{Cl})$} \\
\hline $\begin{array}{l}\text { Intrahepatic } \\
\text { cholangiocarcinoma }\end{array}$ & $0.58(0.30-0.89)$ & $0.14(0-0.30)$ & $0.09(0-0.18)$ & $0.05(0-0.11)$ & $0.07(0-0.18)$ & $0.93(0.56-1.30)$ & \\
\hline $\begin{array}{l}\text { Extrahepatic } \\
\text { cholangiocarcinoma }\end{array}$ & $0.58(0.30-0.89)$ & $0.14(0-0.30)$ & $0.1(0-0.24)$ & $0.09(0-0.24)$ & $0.08(0-0.18)$ & $1.27(0.84-1.70)$ & \\
\hline Gallbladder cancer & $0.79(0.45-1.12)$ & $0.17(0.02-0.35)$ & $0.14(0-0.30)$ & $0.1(0-0.24)$ & $0.07(0-0.18)$ & $0.98(0.61-1.35)$ & \\
\hline Ampullary cancer & $0.32(0.09-0.51)$ & $0.09(0-0.24)$ & $0.05(0-0.11)$ & $0.06(0-0.18)$ & $0.06(0-0.18)$ & $0.58(0.29-0.87)$ & \\
\hline
\end{tabular}




\begin{tabular}{|c|c|c|}
\hline \multirow[b]{2}{*}{ Risk factor } & \multicolumn{2}{|c|}{$\mathrm{HR}^{\star}(95 \% \mathrm{Cl})$} \\
\hline & Univariate analysis & $\begin{array}{l}\text { Multivariate } \\
\text { analysis }\end{array}$ \\
\hline Sex (male v. female) & $1.03(0.97-1.08)$ & $1.1(1.04-1.17)$ \\
\hline Age (per 1-yr increase) & $1.01(1.01-1.02)$ & $1.01(1.01-1.01)$ \\
\hline Chemotherapy (yes v. no) & $0.75(0.70-0.80)$ & $0.65(0.60-0.70)$ \\
\hline Surgery (yes v. no) & $0.34(0.31-0.36)$ & $0.40(0.37-0.44)$ \\
\hline \multicolumn{3}{|l|}{ Tumour type } \\
\hline Ampullary cancer (reference) & 1.0 & 1.0 \\
\hline Intrahepatic cholangiocarcinoma & $2.61(2.38-2.87)$ & $2.06(1.86-2.28)$ \\
\hline Extrahepatic cholangiocarcinoma & $1.67(1.52-1.84)$ & $1.71(1.55-1.89)$ \\
\hline Gallbladder cancer & $1.72(1.57-1.88)$ & $1.45(1.32-1.59)$ \\
\hline No. of biliary drains (per 1-drain increase) & $1.0(0.99-1.02)$ & $0.97(0.95-0.98)$ \\
\hline Stage IV (v. stages I-III) & $3.32(3.13-3.53)$ & $2.47(2.30-2.66)$ \\
\hline $\begin{array}{l}\text { Charlson Comorbidity Index score (per 1-point } \\
\text { increase) }\end{array}$ & $1.1(1.09-1.11)$ & $1.09(1.08-1.10)$ \\
\hline Diagnosis in 2010 onward (v. before 2010) & $1.02(0.96-1.07)$ & $0.84(0.79-0.89)$ \\
\hline $\begin{array}{l}\text { Driving time to nearest hepatopancreatobiliary } \\
\text { surgeon } \geq 120 \mathrm{~min}(\mathrm{v} .<120 \mathrm{~min})\end{array}$ & $1.06(0.99-1.15)$ & $1.27(1.17-1.37)$ \\
\hline \multicolumn{3}{|l|}{$\begin{array}{l}\text { Neighbourhood education level (\% with high } \\
\text { school or above) }\end{array}$} \\
\hline$<75$ (reference) & 1.0 & 1.0 \\
\hline $75-85$ & $0.92(0.87-0.99)$ & $0.93(0.86-1.00)$ \\
\hline$>85$ & $0.97(0.91-1.04)$ & $0.96(0.88-1.05)$ \\
\hline \multicolumn{3}{|l|}{$\begin{array}{l}\text { Neighbourhood income level (average annual } \\
\text { income, \$) }\end{array}$} \\
\hline$<35000$ (reference) & 1.0 & 1.0 \\
\hline $35000-50000$ & $0.96(0.90-1.03)$ & $1.03(0.96-1.10)$ \\
\hline$>50000$ & $1.02(0.95-1.09)$ & $1.09(0.99-1.19)$ \\
\hline $\begin{array}{l}\text { Note: } \mathrm{HR}=\text { hazard ratio. } \\
{ }^{*} \text { Represents the ratio of the death rates between the con } \\
\text { binary) or the logarithm of the change in death rate per } u \\
\text { continuous). }\end{array}$ & $\begin{array}{l}\text { roups of the independe } \\
\text { of the independent var }\end{array}$ & $\begin{array}{l}\text { able (if the variable is } \\
\text { if the variable is }\end{array}$ \\
\hline
\end{tabular}

gallbladder cancer and ampullary cancer who had surgery remained stable, whereas the proportion of patients with intrahepatic cholangiocarcinoma who underwent resection increased, from $18.8 \%$ before 2010 to $36.6 \%$ from 2010 onward $(p=0.001)$. Chemotherapy was administered to more patients from 2010 onward than before 2010 for extrahepatic cholangiocarcinoma $(39.7 \%$ v. $16.0 \%, p<0.001)$, gallbladder cancer $(35.7 \%$ v. $13.2 \%, p<0.001)$ and ampullary cancer (18.4\% v. $8.0 \%, p=0.002)$ but not intrahepatic cholangiocarcinoma $(25.0 \%$ v. $24.8 \%, p=0.4)$.

We evaluated secondary outcomes as a function of driving time to tertiary and quaternary care centres (Table 4 and Supplementary Table S3, Appendix 1). The proportion of patients with stage IV disease (a surrogate for delayed diagnosis) was not affected by driving time (odds ratio [OR] 0.86 ,
95\% CI 0.63-1.19). Proximity to specialty care did affect treatments delivered: patients living 120 minutes or more from the nearest cancer centre were less likely than those living less than 120 minutes away to receive chemotherapy (OR 0.51 , 95\% CI 0.29-0.88). The likelihood of having surgery and receiving only best supportive care were unrelated to residence.

Because survival could be affected by timely access to gastroenterology or interventional radiology if a complication such as biliary sepsis occurred, we tracked the number of biliary drainage procedures. A total of 2027 drains were inserted in 861 patients. There was no difference in the average number of biliary drainage procedures per person between patients who lived less than 120 minutes away and those who lived 120 or more minutes away (1.3 v. 1.2 drains per person, 


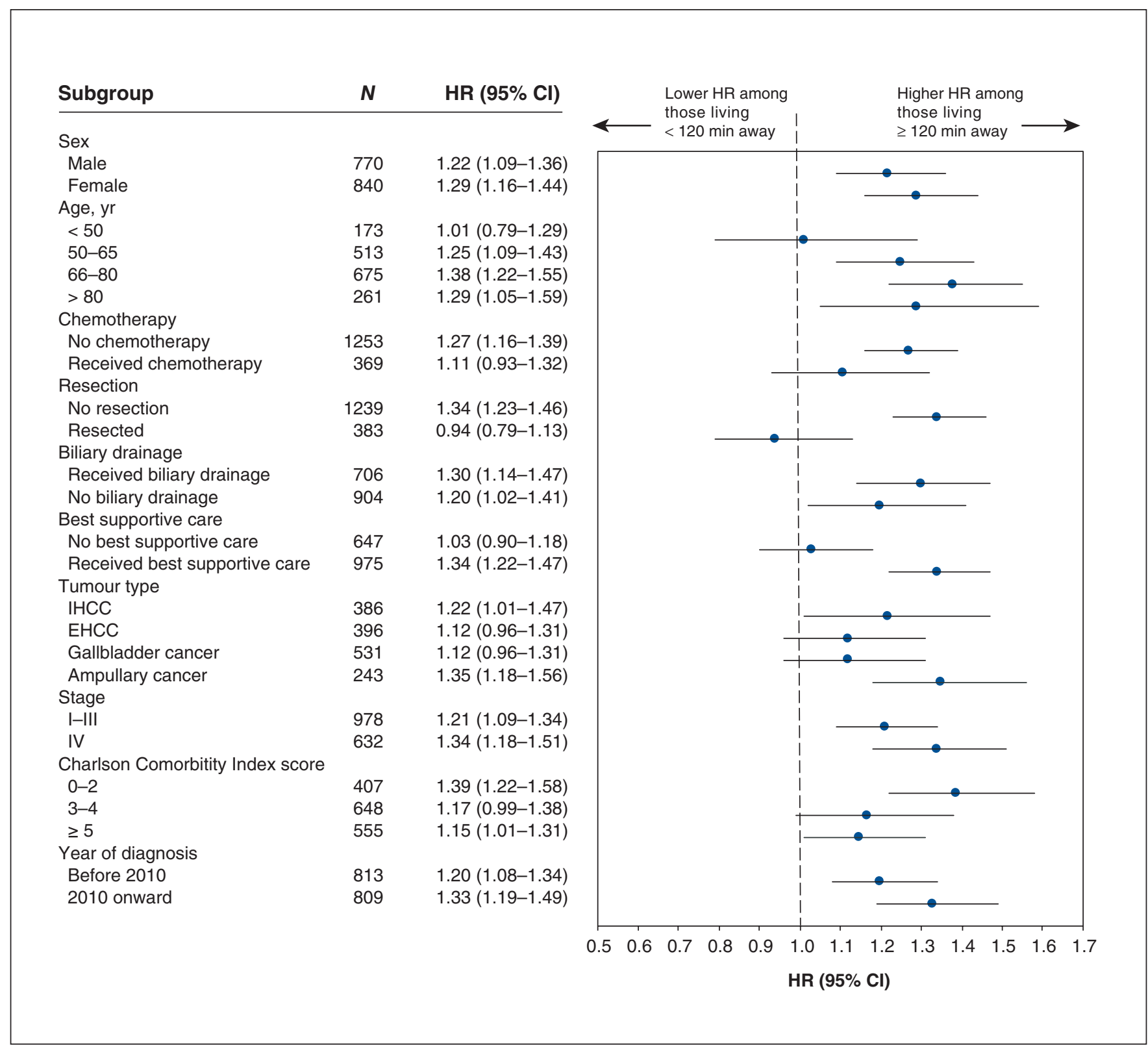

Figure 2: Forest plot depicting the effect of driving time to the nearest hepatopancreatobiliary surgical centre on survival in various subgroups. A hazard ratio $(\mathrm{HR})$ less than 1.0 indicates increased survival. Note: $\mathrm{Cl}=$ confidence interval, EHCC $=$ extrahepatic cholangiocarcinoma, IHCC $=$ intrahepatic cholangiocarcinoma.

$p=0.6)$ or in the proportion who had 2 or more drainage procedures $(56.0 \%$ v. $55.8 \%, p=0.7)$. Unexpectedly, in the final 8 weeks of life, the probability of having a biliary drainage procedure was slightly higher among patients who lived 120 minutes or more (v. < $120 \mathrm{~min})$ away $(19.8 \%$ v. $15.7 \%$, $p=0.08$, adjusted for age, sex, stage, tumour type, comorbidities, income and education level).

\section{Physician visits and patterns of care as a function of residence}

The 1610 patients had 117381 physician encounters. The highest concentration of visits occurred in the final 8 weeks of life (Supplementary Figure S1, A, Appendix 1). The number of visits to physicians was not significantly different during any of the time intervals between patients who lived less than 120 minutes from the nearest hepatopancreatobiliary surgeon and those who lived 120 or more minutes away. However, in the period following diagnosis, there was a higher frequency of emergency department visits among patients who lived 120 minutes or more from the nearest hepatopancreatobiliary surgeon than among those who lived less than 120 minutes away ( 0.86 v. 0.15 visits/person per $4 \mathrm{wk}, p<0.001)$. This was particularly prominent among patients treated with chemotherapy and those who received best supportive care (Supplementary Figure S1, B, Appendix 1). 
Table 4: Multivariate analysis of association between driving time to the nearest hepatopancreatobiliary surgical centre and secondary outcomes (stage IV disease, chemotherapy, surgery and biliary drainage)

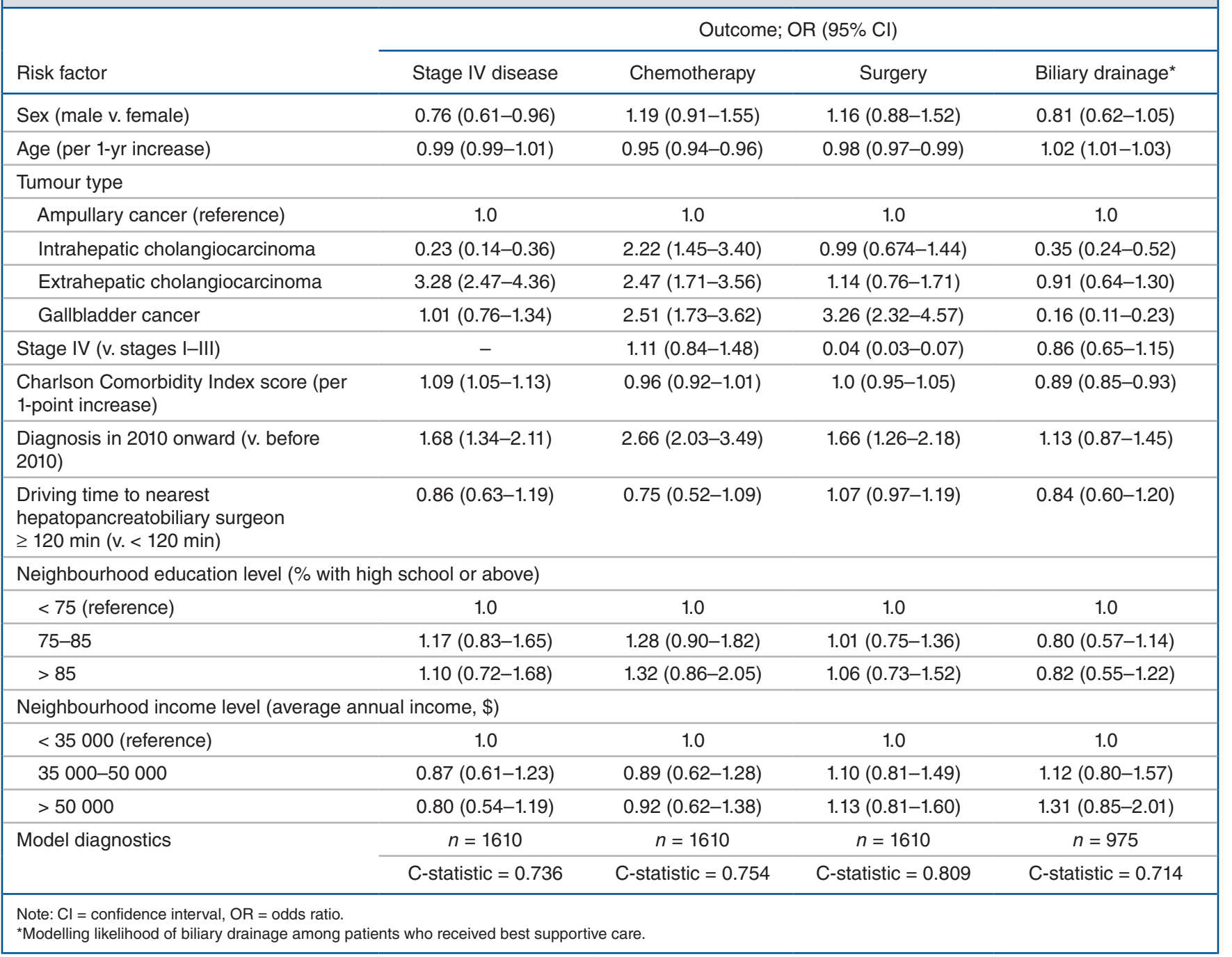

\section{Interpretation}

In this comprehensive exploration of the association of proximity to specialty care and survival, treatment and use of health care services among patients with biliary cancer, our population-based, detailed data set provides insight on patient experiences and the effects of accessibility to care, with patients living far from hepatopancreatobiliary surgical centres and cancer centres generally having worse survival. Given the complexity of managing patients with biliary malignant disease, this is not surprising. Unexpected was the subgroup most affected: the deleterious effects of living remotely were particularly pronounced among patients who required biliary drainage and received best supportive care. This subgroup is particularly susceptible to biliary sepsis, which can lead to precipitous clinical deterioration in the absence of timely management.

The effects of proximity to specialist care are complex and are influenced by the health care system, socioeconomic factors and the disease process. In the United States, some stud- ies have shown that patients travelling to high-volume cancer centres had improved survival compared to those who chose closer, lower-volume care facilities. ${ }^{12-15}$ In those studies, where there was variable access owing to differences in health care insurance, improved survival may have been subject to "travel" 16 or "referral" 17 bias. That is, patients travelling farther to seek care were more capable of receiving complex treatments. In contrast, a United Kingdom study showed worse survival among patients with cancer who had greater travel burden. ${ }^{18}$ Patients who underwent surgery for extrahepatic cholangiocarcinoma at one high-volume US institution had worse outcomes when they travelled large distances. ${ }^{19}$ Our data, derived from a publicly funded health care system, would be expected to remove the effects of health insurance disparities on treatment choices, ${ }^{20,21}$ but although the effects of socioeconomic factors (education and income levels) 22,23 may be smoothed out, they are not completely eliminated.

The trend toward centralization of surgical management of patients with cancer who require advanced and sophisticated 
treatments ${ }^{24,25}$ appears most apparent for those who need continuous management of complications of malignant disease, such as those with biliary cancer. Similarly, delivering chemotherapy to these patients requires a high level of expertise and support to manage complications. Centralization challenges the delivery of timely and appropriate care for rural patients.

\section{Limitations}

First, biliary cancers are rare, and therefore the study population was small despite the fact that the study was longitudinal and population-based. Second, Alberta has a relatively low population:area ratio relative to other provinces in Canada, and therefore the absolute number of patients who live remotely is small. The effects that we observed may be exacerbated in larger provinces, where the distances to advanced care centres are greater. Third, the findings stem from a constituency with universal health care, so the effects of geography may differ in constituencies with variability in health care insurance. Fourth, given the retrospective nature of the study and data availability, we were not able to address all the potential factors that affect survival. In interpreting our findings, one should also consider limits in the validity of administrative data. Fifth, previous publications did not provide any a priori information on the effects of driving time. We acknowledge that different categorizations may lead to different results. For this reason, we analyzed driving time as a continuous variable in the model. The results showed that every 1-minute increment of driving time was associated with worse survival. Thus, the driving time categories we selected would not change the conclusion and served as a meaningful way of conveying the results. Finally, we did not explore the effects of ethnicity on the studied outcomes because data are not reliably available. For example, Indigenous Peoples may be disproportionately affected by health care disparities.

\section{Conclusion}

In this cohort, geography and accessibility to specialty care affected survival in patients with biliary cancer. Further study is required to understand how patients with biliary drains who receive best supportive care are affected by proximity to specialty care. This will aid in the identification of strategies to provide improved care for this subgroup who are particularly affected.

\section{References}

1. de Groen PC, Gores GJ, LaRusso NF, et al. Biliary tract cancers. N Engl 7 Med 1999;341:1368-78.

2. Wiggers JK, Groot Koerkamp B, Cieslak KP, et al. Postoperative mortality after liver resection for perihilar cholangiocarcinoma: development of a risk score and importance of biliary drainage of the future liver remnant. $7 \mathrm{Am}$ Coll Surg 2016;223:321-31.e1.

3. Jarnagin WR, Fong Y, DeMatteo RP, et al. Staging, resectability, and outcome in 225 patients with hilar cholangiocarcinoma. Ann Surg 2001;234:507-17, discussion 17-9.

4. Valle J, Wasan H, Palmer DH, et al. Cisplatin plus gemcitabine versus gemcitabine for biliary tract cancer. N Engl f Med 2010;362:1273-81.

5. Lai EC, Chu KM, Lo CY, et al. Choice of palliation for malignant hilar biliary obstruction. Am f Surg 1992;163:208-12.

6. Targarona EM, Ayuso RM, Bordas JM, et al. Randomised trial of endoscopic sphincterotomy with gallbladder left in situ versus open surgery for common bileduct calculi in high-risk patients. Lancet 1996;347:926-9.
7. Chopra KB, Peters RA, O’Toole PA, et al. Randomised study of endoscopic biliary endoprosthesis versus duct clearance for bileduct stones in high-risk patients. Lancet 1996;348:791-3.

8. Quan H, Sundararajan V, Halfon P, et al. Coding algorithms for defining comorbidities in ICD-9-CM and ICD-10 administrative data. Med Care 2005; 43:1130-9.

9. Quan H, Li B, Couris CM, et al. Updating and validating the Charlson Comorbidity Index and score for risk adjustment in hospital discharge abstracts using data from 6 countries. Am 7 Epidemiol 2011;173:676-82.

10. Cunningham CT, Cai P, Topps D, et al. Mining rich health data from Canadian physician claims: features and face validity. BMC Res Notes 2014;7:682.

11. Google Maps JavaScript API. Available: https://developers.google.com/maps/ documentation/javascript/ (accessed 2019 Jan. 8).

12. Lamont EB, Hayreh D, Pickett KE, et al. Is patient travel distance associated with survival on phase II clinical trials in oncology? $\mathcal{F}$ Natl Cancer Inst 2003; 95: $1370-5$.

13. Lidsky ME, Sun Z, Nussbaum DP, et al. Going the extra mile: improved survival for pancreatic cancer patients traveling to high-volume centers. Ann Surg 2017;266:333-8.

14. Wasif N, Chang YH, Pockaj BA, et al. Association of distance traveled for surgery with short- and long-term cancer outcomes. Ann Surg Oncol 2016;23: 3444-52.

15. Speicher PJ, Englum BR, Ganapathi AM, et al. Traveling to a high-volume center is associated with improved survival for patients with esophageal cancer. Ann Surg 2017;265:743-9.

16. Etzioni DA, Fowl RJ, Wasif N, et al. Distance bias and surgical outcomes. Med Care 2013;51:238-44.

17. Paltiel O, Ronen I, Polliack A, et al. Two-way referral bias: evidence from a clinical audit of lymphoma in a teaching hospital. 7 Clin Epidemiol 1998;51: 93-8.

18. Turner M, Fielding S, Ong Y, et al. A cancer geography paradox? Poorer cancer outcomes with longer travelling times to healthcare facilities despite prompter diagnosis and treatment: a data-linkage study. Br 7 Cancer 2017;117: 439-49.

19. O'Connor SC, Mogal H, Russell G, et al. The effects of travel burden on outcomes after resection of extrahepatic biliary malignancies: results from the US Extrahepatic Biliary Consortium. 7 Gastrointest Surg 2017;21:2016-24.

20. Niu X, Roche LM, Pawlish KS, et al. Cancer survival disparities by health insurance status. Cancer Med 2013;2:403-11.

21. Robbins AS, Chen AY, Stewart AK, et al. Insurance status and survival disparities among nonelderly rectal cancer patients in the National Cancer Data Base. Cancer 2010;116:4178-86.

22. Gorey KM, Luginaah IN, Bartfay E, et al. Effects of socioeconomic status on colon cancer treatment accessibility and survival in Toronto, Ontario, and San Francisco, California, 1996-2006. Am F Public Health 2011;101:112-9.

23. Gorey KM. Breast cancer survival in Canada and the USA: meta-analytic evidence of a Canadian advantage in low-income areas. Int 7 Epidemiol 2009;38: 1543-51.

24. Aquina CT, Probst CP, Becerra AZ, et al. High volume improves outcomes: the argument for centralization of rectal cancer surgery. Surgery 2016;159: 736-48.

25. Stitzenberg KB, Sigurdson ER, Egleston BL, et al. Centralization of cancer surgery: implications for patient access to optimal care. 7 Clin Oncol 2009;27: 4671-8.

Affiliations: Beijing You-An Hospital (Xu), Capital Medical University, Beijing, China; Departments of Community Health Sciences (Xu, Dixon) and Surgery (Xu, Dixon, Ball, Sutherland, Bathe), University of Calgary; Innervative Strategies (Steckle), Calgary, Alta.; Department of Oncology (Lui, Spratlin), University of Alberta, Edmonton, Alta.; Department of Oncology (Dixon, Ball, Sutherland, Bathe), University of Calgary, Calgary, Alta.

Contributors: Yuan Xu, Sue Steckle, Arthur Lui and Oliver Bathe contributed to study conception and design. Yuan Xu, Sue Steckle and Oliver Bathe acquired the data. Yuan Xu, Arthur Lui, Elijah Dixon and Jennifer Spratlin analyzed the data. Sue Steckle, Arthur Lui, Elijah Dixon, Chad Ball, Francis Sutherland, Jennifer Spratlin and Oliver Bathe interpreted the data. Yuan $\mathrm{Xu}$ and Oliver Bathe drafted the manuscript, and Sue Steckle, Arthur Lui, Elijah Dixon, Chad Ball, Francis Sutherland, Jennifer Spratlin and Oliver Bathe critically revised it for important intellectual content. All of the authors gave final approval of the version to be published and agreed to be accountable for all aspects of the work.

Supplemental information: For reviewer comments and the original submission of this manuscript, please see www.cmajopen.ca/content/7/1/ E131/suppl/DC1. 